IJMS 16 (2), 199-224 (2009)

\title{
THE IMPACT OF A PRICE CHANGE ON CONSUMER CHOICE OF AUTOMOBILES
}

\author{
MUSZAFARSHAH MOHD MUSTAFA \\ NOR AZAM ABDUL RAZAK \\ College of Arts and Sciences \\ Universiti Utara Malaysia
}

\begin{abstract}
This paper studies the impact of price change on the consumer choice of four selected automobiles in Malaysia: Saga 1.3cc, Saga 1.5cc, Wira 1.3cc, and Wira 1.5cc. The data were obtained from automobile reports compiled by the Malaysian Automotive Association (MAA), and analysed using the conditional and nested logit models. Our empirical analysis produced several key findings. Firstly, the sales of Saga 1.3cc appeared to be affected by change in the price of Wira 1.3cc only, and vice versa. Secondly, the sales of Saga 1.5cc did not appear to be affected by change in the price of other models. Finally, the sales of Wira $1.5 \mathrm{cc}$ also did not appear to be affected by change in the price of other models. Taken together, these results suggested that, except for Saga 1.3cc and Wira 1.3cc, there is little or no evidence that all of the car models under consideration are substitutes to each other in a pairwise comparison.
\end{abstract}

Keywords: Vehicle-type choice; Saga; Wira; Conditional logit, Nested logit.

\begin{abstract}
ABSTRAK
Artikel ini mengkaji kesan perubahan harga terhadap pilihan pengguna bagi empat kereta nasional terpilih di Malaysia: Saga 1.3cc, Saga 1.5cc, Wira 1.3cc, dan Wira 1.5cc. Data diperoleh daripada laporan-laporan kereta tahunan yang dikumpul oleh Malaysian Automotive Association (MAA), dan dianalisis dengan menggunakan model conditional dan nested logit. Kajian empirik yang dilakukan menghasilkan beberapa dapatan utama. Pertama, terdapat bukti bahawa jualan Saga 1.3cc dipengaruh perubahan harga Wira 1.3cc sahaja, dan begitu juga sebaliknya. Kedua, tiada bukti bahawa jualan Saga 1.5cc dipengaruh perubahan harga bagi model-model lain. Akhir sekali, tiada bukti bahawa jualan
\end{abstract}


Wira 1.5cc dipengaruh perubahan harga bagi model-model lain. Ketiga-tiga dapatan ini menyarankan bahawa, selain daripada Saga 1.3cc dan Wira 1.3cc, tidak ada bukti yang mencukupi bahawa model-model kereta yang dikaji bersifat pengganti di antara satu sama lain.

Keywords: Pilihan jenis kenderaan; Saga; Wira; Conditional logit; Nested logit.

\section{INTRODUCTION}

For last two decades, growth in sales of automobiles in Malaysia has been impressive. According to the Malaysian Automotive Association (MAA, 2007), the total number of passenger vehicles registered in Malaysia has grown at on average annual rate of $10.48 \%$ during the period 19812006. During the same period, the population of Malaysia has grown (1) at an average annual rate of $2.65 \%$ (MOF, various issues). Together, the growth rate of both variables implies that car ownership in Malaysia has increased over time. According to the Ministry of Development Authority (MIDA, 2007), Malaysia currently enjoys a car ownership ratio of 200 cars for every 1000 population (or 1:5). This fact suggests that, if a typical household consists of five people, then, in principle, every household in Malaysia owns a car.

.

Although the car ownership ratio in Malaysia is quite high, the prices of these cars constitute a large portion of the household income ${ }^{1}$. As such, the average Malaysians are quite sensitive to changes in car prices. This study attempted to investigate this price sensitivity in the national car "market. In particular, we measured the degree in which a consumer's choice of a particular car model is affected by changes in the prices of alternative models. In other words, we sought to measure the marginal effect of a price change of one car model on the choice of alternative models (i.e. the cross-price marginal effect).

This paper is organised as follows. In Section 2, we provide an overview of the automobile industry in Malaysia, while Section 3 reviews the literature related to automobile choice. In Section 4, we discuss the scope of our analysis as well as the methodology and data used in this paper, followed by Section 5 with the results of our empirical analysis. Section 6 discusses the economic and policy implications of our analysis, and Section 7 offers concluding remarks. 


\section{THE AUTOMOBILE INDUSTRY IN MALAYSIA}

Malaysia is a developing country situated in the South East Asia region with a total population of 27.2 million people, total labour force of 10.3 million, per capita GDP of US\$5,145, and GDP growth rate of $6 \%$ (MIDA, 2007). Under the stewardship of the then Prime Minister of Malaysia, Tun Dr. Mahathir Mohammad, Malaysia started to produce its own national cars in 1985 as an import-substitution strategy. The strategy appeared to be successful as sales of passenger cars began to accelerate since then. As shown in Figure 1, data indicated that while the total number of new passenger cars registered in Malaysia has been either stagnant or even declining during the period 1980-1987, it has grown rather steadily since then (let alone the brief, though acute, recessionary period in 1998).

The introduction and promotion of national cars by the government has increased the demand for nationally-made cars. Since their inception in 1985, national cars have persistently dominated the domestic car market. The dominance is clearly visible from Figure 2, where the market share of national cars grew from as low as $47 \%$ when they were first introduced to as high as 93\% in 1999 and 2000. Owing to the Malaysia's participation in AFTA, however, the market share of national cars for later years has declined slightly. In the year 2006, for example, the market share of national cars has fallen to $76 \%$.

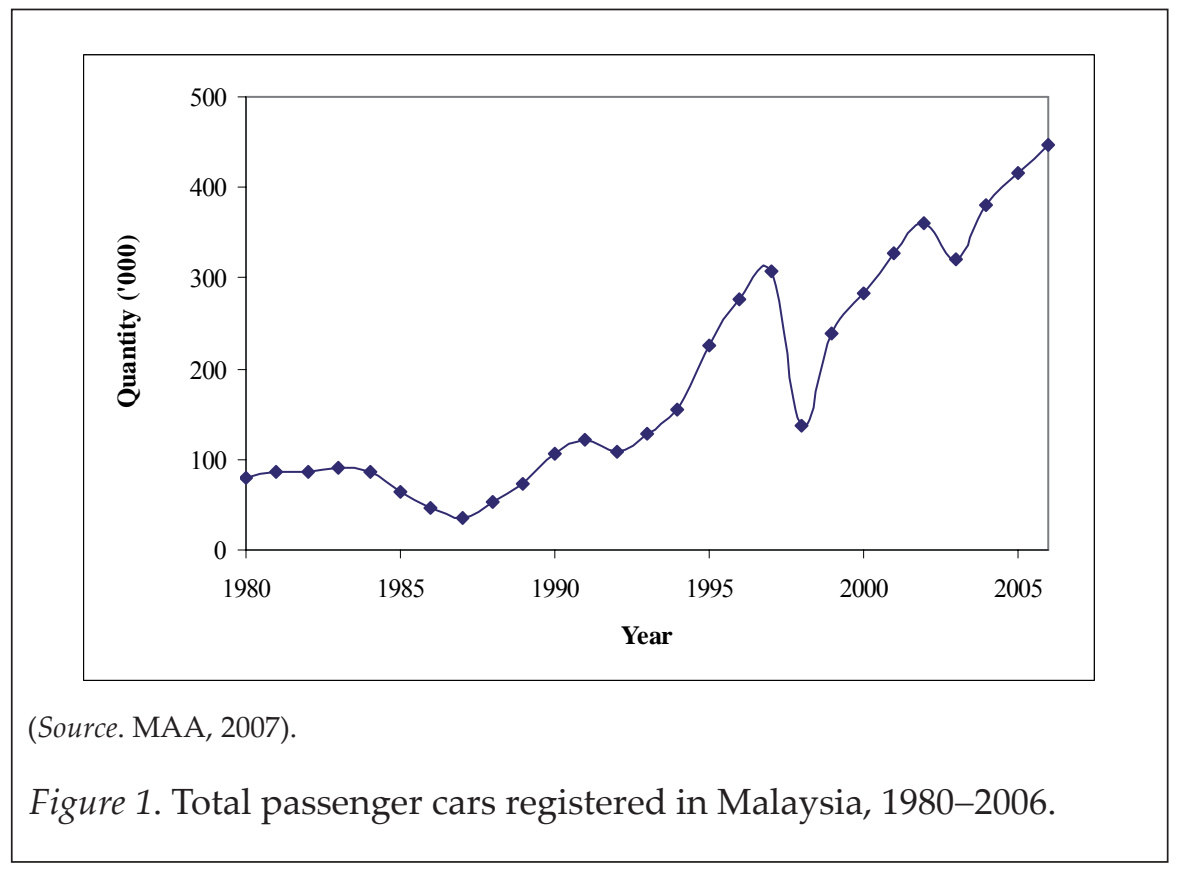




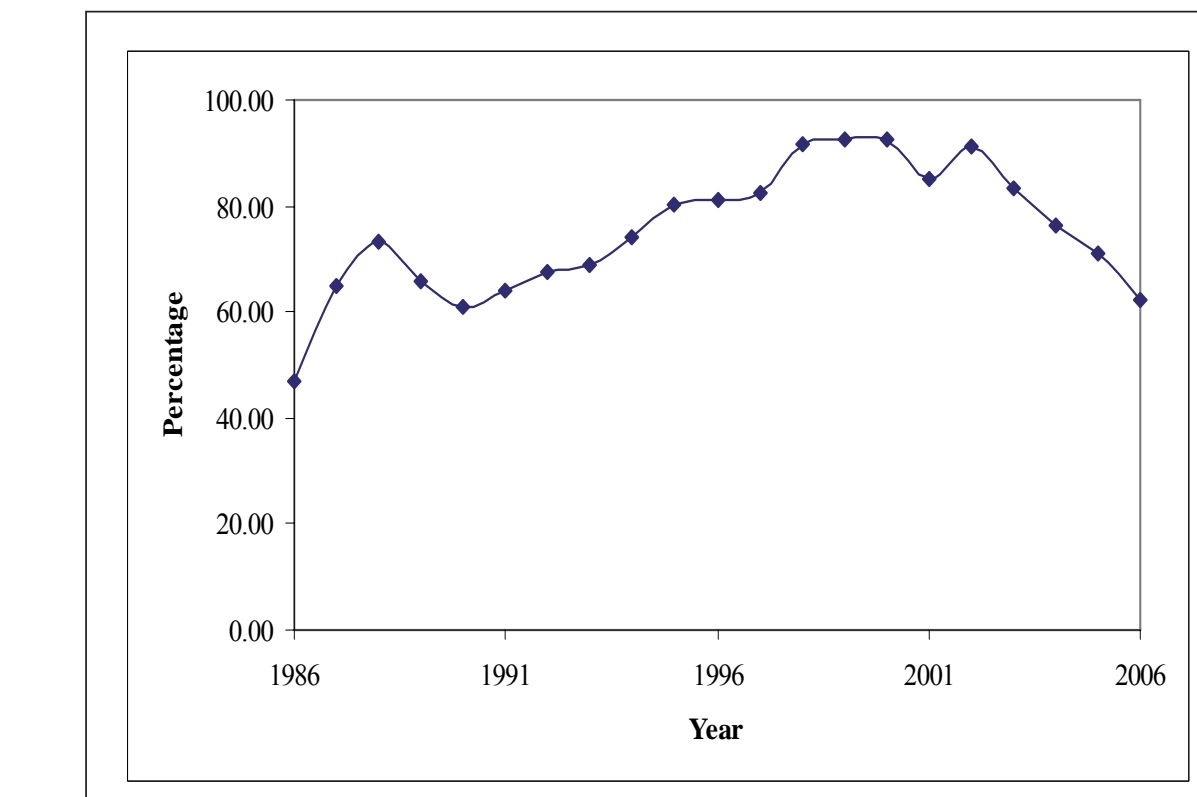

(Source. MAA, 2007).

Figure 2. National passenger cars as a percentage of Total passenger cars Registered in Malaysia, 1986-2006.

DThere are currently four national car producers in Malaysia: Proton, Perodua, Naza, and Inokom. Together, these car makers have rolled out 30 different models, of which 12 models have been produced by Proton, 7 models by Perodua, 6 models by Naza, and 5 models by Inokom. Proton cars are Saga (1986), Wira (1993), Perdana (1995), Satria (1995), Putra (1996), Tiara (1996), Waja (2000), Juara (2002), Arena (2002), Gen-2 (2004), Savvy (2005), and Persona (2007)2. Perodua cars are Kancil (1994), Rusa (1996), Kembara (1998), Kenari (2000), Kelisa (2001), Myvi (2005) and Viva (2007). Naza cars are Ria (2004), Citra (2005), Sorento (2005), Bestari (2006), Suria (2006), and Sutera (2006). Inokom cars are Lorimas (2002), Permas (2002), Atos (2004), Matrix (2004), and Getz (2006)³.

In December 2007, the Malaysian Government came up with a comprehensive National Automotive Policy outlining its objectives in making and promoting the automotive industry as a major contributor to the growth of the Malaysian economy. It was hoped that, with this policy, Malaysia would eventually become an important hub for automobile production and distribution for the region and in the world. 


\section{LITERATURE REVIEW}

A standard tool of analysis in empirical economics is the classical linear regression model (CLRM) based on the ordinary least squares (OLS) estimation method. When the dependent variable is discrete (rather than continuous), however, its values have to be interpreted in a probabilistic sense $^{4}$. As such, its values must be restricted in the $[0,1]$ interval. If we continue to use the OLS-based CLRM, however, it is possible to obtain values of the dependent variable that are either negative or greater than unity, which is implausible. To get around this problem, a discrete choice model (DCM) based on the maximum likelihood (ML) estimation method is employed in lieu of the standard CLRM.

A DCM may take a few forms depending on the number of choices faced by individuals. When the choice is binary, we obtain the simplest form of DCMs known as the binomial logit model. When the are multiple choices, we have two basic forms of DCMs: multinomial logit model and conditional logit model ${ }^{5}$. It is typical to find that the terms conditional logit and multinomial logit are used interchangeably in the literature. In a conditional logit model, the explanatory variables are both individual and alternative-specific, and the coefficients are constant. However, in a multinomial logit model, the explanatory variables are individualspecific only, and the coefficients vary with alternatives. Apparently, the choice between applying a conditional logit model or a multinomial logit model in any analysis hinges upon whether one has access to individualand alternative-specific explanatory variables or just individual-specific explanatory variables.

Our empirical analysis on consumer choice of national automobiles in Malaysia belongs to a class of DCMs known as a vehicle-type choice model. In this model, consumers face and choose among a discrete set of vehicle classes, makes, or models. In making the purchase decision, consumers consider a number of factors such as the price of those vehicles, the features of those vehicles, their own income, and their family size, to name a few. Our simple model was constructed along the same line with previous vehicle-type choice models; a partial list of which includes Lave and Train (1979), Manski and Sherman (1980), Mannering and Winston (1985), Berkovec and Rust (1985) and Choo and Mokhtarian (2004).

The vehicle-type choice model can be grouped into two categories, namely vehicle ownership models and vehicle purchase models, depending 
on whether the chosen vehicle type is considered as already owned or newly bought. Many of these models differ from one another due to the different dependent and explanatory variables employed in them. Most of the models utilised vehicle attributes (such as operating and capital costs, horsepower, and fuel efficiency), household characteristics (such as number of household members, number of vehicles, and household income), principal driver characteristics (such as age, education, and income), and brand loyalty, but it is difficult to compare significant variables across the vehicle type choice models. The most common variable in many of these models is the vehicle price, with many studies revealing its value to be negatively significant. This implies that, all else equal, the higher the price of a vehicle, the lower its choice probability.

-Lave and Train (1979) investigated a car buyer choice among 10 vehicle classes, which includes subcompact, compact, intermediate, standard, and luxury class cars, among others. The data were obtained from interviews on a sample of 541 new car buyers in seven U.S. cities in the summer of 1976. Employing a multinomial logit model (vehicle-type -purchased model), they found that the following explanatory variables are statistically significant: the ratio of purchase price to income, the vehicle's weightxage, the number of household members (for certain car classes), and the number of vehicles.

Manski and Sherman (1980) analysed the household motor vehicle -holdings from a 1976 survey data done by Survey Research Centre's Dinter of 1200 single-vehicle or two-vehicle households. The dependent variable was the chosen alternative ( 1 or 2 vehicles) plus 25 alternative makes/models/vintages which were randomly selected from 600 vehicle types. Using a multinomial logit model (vehicle-holdings model), "they found that the purchase price, the number of seats, the vehicle's weightxage, acceleration time, the luggage space, the scrappage rate, and transaction and search costs influenced the choices that households make.

A study by Mannering and Winston (1985) examined household vehicle ownership and utilisation by employing a multinomial logit model (vehicle holdings). Data were sourced from a U.S. household sample obtained by combining two surveys; the National Interim Energy Consumption Survey and the Household Transportation Panel. Information on 3,842 single-vehicle or two-vehicle households was obtained during November and December 1978. The dependent variable was the chosen alternative (one or two vehicles) plus nine alternative makes/models/vintages which were randomly selected from 2000 vehicle 
types. Their result showed that the ratio of purchase price to income, the ratio of operating cost to income, and lagged utilisation (since utilisation of vehicles in the past would influence household decision) of the same vehicle/make are significant explanatory variables.

A nested logit model of vehicle holdings was employed by Berkovec and Rust (1985) by applying 1978 U.S. data from 237 single-vehicle households. The dependent variable for the upper level of the nested logit was the vehicle age groups (new: 1977-1978, mid: 1973-1976, old: 19671972), while the lower level was the five vehicle classes (subcompact, compact, intermediate, standard, and luxury/sports). Their findings showed that the purchase price, operating cost, the number of seats, the vehicle's age, the turning radius (a measure of maneuverability of the vehicle) in urban, setting, and the ratio of horsepower to weight significantly influenced household choices.

An interesting study by Choo and Mokhtarian (2004) tried to incorporate consumers' travel attitudes, personality, lifestyle, and mobility, in addition to the usual demographic factors, as variables that may affect the vehicle type choice. The survey data were obtained from 1904 households in the San Francisco Bay Area in May and June 1998. The dependent variables were small car, compact car, mid-sized car, large car, luxury car, minivan/ van, pickup, and SUV. The explanatory variables were grouped into five categories; mobility, travel liking, attitudes, personality, lifestyle, and demographics. Applying a multinomial logit model, they found that the travel attitude factors (travel dislike and pro-high density), personality factors (organiser and calm), all lifestyle factors except family/community oriented, mobility factors (objective and subjective), travel liking, and all demographic characteristics were significant in the model.

\section{SCOPE, METHODOLOGY, AND DATA}

Although there exists a relatively large menu of national automobile models in Malaysia, computational burden and the paucity of price data necessitate that we restrict the choice to a relatively few models. A question arises on how we choose these few models. A natural way is by selecting the best-selling models on the road. Once we adopt this approach, one obvious measure of the best-selling models is the annual average sales volume. Based on this measure, we found that the top five best-selling cars are Wira, Myvi, Kancil, Saga, and Waja (see Table 1 in Appendix A). 
Although this measure makes much sense, the inclusion of Myvi significantly limits the time series dimension of the data to be analysed since Myvi did not appear until the year 20056. For this reason, we adopted an alternative measure of the best-selling models: the total sales volume. Based on this measure, we observed that the top five best-selling cars are Saga, Wira, Kancil, Waja, and Kelisa (see Table 1 in Appendix A for the calculation of the best-selling models based on both measures).

Once we adopted this alternative measure, our selection of cars was narrowed down to five models. Based on the price range of these five models, it appearred that there exist three segments of the car market, one for Saga and Wira, another one for Kancil and Kelisa, and the last one for Waja ${ }^{7}$. Our research was concerned with the price changes in the same segment of the automobile market. Thus, we decided to choose Saga and Wira since they are more popular than Kancil and Kelisa, and that these car models are purchased by the average Malaysians (the (1) middle-income group).

(1)

In general, both of these models come in three different features: engine size (1.3cc and 1.5cc), design type (sedan and aeroback), and transmission type (manual and automatic). Upon closer scrutiny, however, we found the following (see Figure 3 in Appendix B): firstly, for both Saga 1.3cc and Wira 1.3cc, there are no automatic transmissions (for either sedan or aeroback version). Secondly, for Saga $1.5 \mathrm{cc}$, there is no manual transmission for its aeroback version. Thirdly, for Saga 1.5cc, the price data of its manual transmission for the sedan version are not available. Finally, for Wira 1.5cc, the price data for automatic aeroback version are available for a few scattered years.

For these reasons, our analysis was restricted in the two following ways: firstly, for the $1.3 \mathrm{cc}$ version, we studied the sedan design and manual transmission, and Secondly, for $1.5 \mathrm{cc}$ version, we only analysed the sedan design and automatic transmission. In other words, consumers make the following four choices: Saga 1.3cc (sedan and manual), Saga 1.5cc (sedan and automatic), Wira 1.3cc (sedan and manual), or Wira $1.5 \mathrm{cc}$ (sedan and automatic).

Based on the preceding discussion, the dependent variable can be defined as the choice of a particular car model $j$ made by a consumer $i$, denoted by 


$$
y_{i}=\left\{\begin{array}{l}
1 \text { if } i \text { buys Saga } 1.3 c c \text { (or } S 13) \\
2 \text { if } i \text { buys Saga } 1.5 c c(\text { or } S 15) \\
3 \text { if } i \text { buys Wira } 1.3 c c(\text { or } W 13) \\
4 \text { if } i \text { buys Wira } 1.5 c c(\text { or } W 15)
\end{array}\right.
$$

and the explanatory variables are the prices of those car models, denoted by

$$
\mathrm{x}_{i j}=\left(x_{i 1}, x_{i 2}, x_{i 3}, x_{i 4}\right)
$$

where $x_{i 1}$ is the price of S13 faced by consumer $i, x_{i 2}$ is the price of S15 faced by consumer $i$, and so on ${ }^{8}$.

Given the categorical nature of the dependent variable, as well as the individual- and alternative-specific nature of the explanatory variables, our model can be specified as the probability of buying any particular car model $j(j=1,2,3,4)$ by consumer $i(i=1,2, \ldots, N)$, which is expressed by

$$
\operatorname{Prob}\left(y_{i}=j \mid \mathrm{x}_{\mathrm{ij}}^{\prime} \beta\right)=\mathrm{F}\left(\mathrm{x}_{\mathrm{ij}}^{\prime} \beta\right)
$$

where $F($.$) is a cumulative distribution function which assumes the$ logistic form,

$$
F\left(x_{i j}^{\prime} \beta\right)=\frac{\exp \left(x_{i j}^{\prime} \beta\right)}{\sum_{j=1}^{4} \exp \left(x_{i j}^{\prime} \beta\right)},
$$

Substituting Equation 4 into Equation 3, we obtained a complete specification for the conditional logit model:

$$
\operatorname{Prob}\left(y_{i}=j \mid \mathrm{x}_{\mathrm{ij}}^{\prime} \beta\right)=\frac{\exp \left(\mathrm{x}_{\mathrm{ij}}^{\prime} \beta\right)}{\sum_{\mathrm{j}=1}^{4} \exp \left(\mathrm{x}_{\mathrm{ij}}^{\prime} \beta\right)} .{ }^{9}
$$

The cross-price marginal effects can be obtained by differentiating Equation 5 with respect to the price variable of interest. In practice, the cross-price marginal effects are approximated by the cross-price discrete change, which can be expressed as follows: 


$$
\frac{\Delta \operatorname{Prob}\left(y_{i}=j \mid \mathrm{x}_{\mathrm{ij}}^{\prime} \beta\right)}{\Delta x_{i k}}=\operatorname{Prob}\left(\mathrm{y}_{\mathrm{i}}=\mathrm{j} \mid \overline{\mathrm{x}}_{\mathrm{ij}}^{\prime} \beta, \overline{\mathrm{x}}_{\mathrm{ik}}+\Delta \mathrm{x}_{\mathrm{ik}}\right)-\operatorname{Prob}\left(\mathrm{y}_{\mathrm{i}}=\mathrm{j} \mid \overline{\mathrm{x}}_{\mathrm{ij}}^{\prime} \beta\right),
$$

where the bar over the price variables indicates that the prices are evaluated at some specific values (usually their mean values). Equation 6 states that the change in the probability of choosing model $j$ (by consumer i) due to a change in the price of model $k$ is given by the difference in the probability of choosing model $j$ when the price of model $k$ changes by a discrete amount, $\Delta x_{i k}^{10}$. The cross-price discrete-change can help us answer the following questions:

What is the impact on the probability of buying $S 13$ by consumer $i$ of a $10 \%$ increase in the price of a) S15, b) W13, or c) W15?

What is the impact on the probability of buying S15 by consumer $i$ of a $10 \%$ increase in the price of a) S13, b) W13, or c) W15?

What is the impact on the probability of buying W13 by consumer $i$ of a $10 \%$ increase in the price of a) S13, b) S15, or c) W15?

What is the impact on the probability of buying W15 by consumer $i$ of a $10 \%$ increase in the price of a) S13, b) S15, or c) W13?

The cross-price discrete change can be positive or negative, implying whether the models under consideration are substitutes or complements. Suppose we pick S13 and W13. If an increase in the price of W13 has a positive impact on the choice of S13 (and vice versa), then they are substitutes ${ }^{11}$. Conversely, if an increase in the price of W13 has a negative impact on the choice of S13 (and vice versa), then they are complements. Accordingly, the sign of the cross-price discrete change (there are nine of them) conveys information on whether two models are substitutes or complements.

Apart from the sign, the magnitude of the cross-price discrete change may shed light on the degree of substitutability or complementarity of any two models. For example, if a 10\% increase in the price of S15 raises the probability of buying S13 by 5\% and a 10\% increase in the price of W13 raises the probability of buying S13 by $15 \%$, then W13 is a closer substitute to S13 than S15 is.

The data required for this analysis were obtained from the office of the Malaysian Automotive Association (MAA) in Petaling Jaya. Although the quantity data for automobiles are generally available for the period 
1986-2006, the car price data are missing for some models during certain years. In our case, the paucity of price data for both Saga and Wira models has forced us to restrict the period of analysis to 2000-2002. During this period, the total quantity sold of all four models was 92,138 units. Of this figure, the most popular model was W15 (57.4\%), followed by S13 $(22.1 \%)$, S15 $(10.9 \%)$, and finally W13 $(9.6 \%)$. The breakdown of the quantity sold of these models by years is given in Table 1.

Table 1

Quantity of Saga and Wira Models Sold, 2000-2002

\begin{tabular}{crrrr}
\hline & \multicolumn{2}{c}{ Saga } & \multicolumn{2}{c}{ Wira } \\
\cline { 2 - 5 } Year & $1.3 c c$ & $1.5 c c$ & $1.3 c c$ & $1.5 c c$ \\
\hline 2000 & 8,126 & 4,558 & 2,211 & 17,260 \\
2001 & 8,596 & 3,110 & 3,333 & 16,915 \\
2002 & 3,643 & 2,363 & 3,295 & 18,728 \\
Total & 20,365 & 10,031 & 8,839 & 52,903 \\
\hline
\end{tabular}

Source. Malaysian Automotive Association (MAA, 2007).

\section{EMPIRICAL ANALYSIS}

Given the car purchase data of 92,138 units, we conducted an empirical analysis based on the conditional logit (CL) model in Equation 5. It is important to note that, in a CL model with J choices, every purchase made by a consumer is recorded as $1 \mathrm{xJ}$ observations (since a consumer observes the prices of all four models before he or she chooses any particular model). Hence, if there are $\mathrm{N}$ purchases made, then the total number of observations is equal to NxJ. In our case, $\mathrm{N}=92,318$ and $\mathrm{J}=$ $4^{12}$; hence, $\mathrm{NxJ}=368,552$ ! In view of the fact that the storage capacity for Microsoft Excel is about 65,000 observations, we scaled down the number of purchases to $1 \%$, i.e., $\mathrm{N}=921$ units (in doing so, the number of purchases for each model is reduced to $1 \%$, too). Hence, $\mathrm{NxJ}=3,684$.

\section{Baseline Analysis}

Given the car purchase data for a sample of 3,684 units during the period 2000-2002, we conducted an empirical analysis based on the CL model in Equation (5). As reported in Table 2, the results showed that a) the intercept coefficients (i.e., the estimated coefficients of the first three car models) ${ }^{13}$ enter with negative signs and significant at $1 \%$ level, and b) the (common) slope coefficient (i.e., the estimated coefficient of the price variable) enters with a negative sign and significant at the $1 \%$ level. 
Table 2

Conditional Logit Estimation

\begin{tabular}{cccc}
\hline Variables & Coefficient & Std Error & $\mathrm{z}$ \\
\hline S13 & $-13.0436^{*}$ & 3.6021 & -3.62 \\
S15 & $-8.7237^{*}$ & 2.1116 & -4.13 \\
W13 & $-10.5320^{*}$ & 2.6181 & -4.02 \\
Price & $-1.0878^{*}$ & 0.3241 & -3.36 \\
\hline
\end{tabular}

Note. The asterisk * indicates that the coefficient is significant at the $1 \%$ level.

- The significance of the intercept terms suggests that all of those models are distinct from each other, whereas the significance of the slope terms -implies that price changes are expected to have a significant effect on the choice of any one model. In addition, the negative sign of the intercept terms suggests that W15 is the most popular model on the road (since its intercept is zero while the others are negative), and the negative sign (1) of the slope coefficient indicates that the own-price marginal effects are negative.

Once we have confirmed the sign and significance of the estimated parameters, we proceeded with the cross-price discrete change analysis based on Equation 6. As documented in Table 4, the general result was that an increase in the price of any one model has a positive effect on the -probability of buying any other alternative models. This result suggested that all of those models are substitutes to each other.

\section{Table 3}

Cross-Price and Own-Price Discrete Change

\begin{tabular}{ccccc}
\hline \multirow{2}{*}{$\begin{array}{c}\text { Independent } \\
\text { Variable }\end{array}$} & \multicolumn{5}{c}{ Dependent Variable } \\
\cline { 2 - 5 } & $\mathrm{S} 13$ & $\mathrm{~S} 15$ & $\mathrm{~W} 13$ & $\mathrm{~W} 15$ \\
\hline \multirow{2}{*}{ PS13 } & $-0.1260^{*}$ & $0.0210^{*}$ & $0.0095^{*}$ & $0.0954^{*}$ \\
& $(-5.54)$ & $(4.15)$ & $(8.06)$ & $(5.34)$ \\
\hline \multirow{2}{*}{ PS15 } & $0.0200^{*}$ & $-0.0836^{*}$ & $0.0058^{*}$ & $0.0579^{*}$ \\
& $(4.17)$ & $(-4.09)$ & $(6.19)$ & $(3.79)$ \\
\hline \multirow{2}{*}{ PW13 } & $0.0085^{*}$ & $0.0055^{*}$ & $-0.0388^{*}$ & $0.0248^{*}$ \\
& $(8.14)$ & $(6.67)$ & $(-9.47)$ & $(9.17)$ \\
\hline \multirow{2}{*}{ PW15 } & $0.1369^{*}$ & $0.0878^{*}$ & $0.0396^{*}$ & $-0.2643^{*}$ \\
& $(3.63)$ & $(2.83)$ & $(5.76)$ & $(-3.63)$ \\
\hline
\end{tabular}

Note. Figures in parentheses are the z-values. The asterisk * indicates that the coefficient is significant at the $1 \%$ level. PS13, PS15, PW13, and PW15 refer to the price of the respective models. 
The specific results can be decomposed into the impact of a discrete change in the price of any one model on the probability of buying other car models. Firstly, a rise in the price of S13 by RM1000 is expected to raise the probability of buying S15, W13, and $\mathrm{W} 15 \mathrm{by}, 2.1 \%, 0.95 \%$, and $0.94 \%$, respectively. Secondly, a rise in the price of S15 by RM1000 is expected to raise the probability of buying S13, W13, and W15 by, $2 \%$, $0.58 \%$, and $5.8 \%$, respectively. Thirdly, a RM1000 increase in the price of W13 is expected to increase the probability of buying S13, S15, and W15 by $0.85 \%, 0.55 \%$, and $2.48 \%$, respectively. Finally, a RM1000 increase in the price of W15 is expected to increase the probability of buying S13, S15, and $\mathrm{W} 13$ by $13.7 \%, 8.78 \%$, and $3.96 \%$, respectively.

All of these results indicated that all of the car models are substitutes to each other in a pairwise comparison. However, the degree of substitutability differs markedly (i.e., from as low as $0.55 \%$ to as high as $13.7 \%$ ). If we are willing to accept a $5 \%$ response as the cut-off point between close and distant substitutes, then it is reasonable to conclude that most car models are distant substitutes to one another in a pairwise comparison.

Apart from the cross-price discrete change, we also conducted the ownprice discrete change analysis. We found that a) a RM1000 rise in the price of S13 reduces the probability of buying it by $12.6 \%$, b) a RM1000 rise in the price of $\mathrm{S} 15$ reduces the probability of buying it by $8.36 \%$, and c) a RM1000 rise in the price of W13 reduces the probability of buying it by $3.88 \%$. All of these results were consistent with the predictions of demand theory.

\section{Robustness Analysis}

A major drawback of the CL model is that the model exhibits the property of independence of irrelevant alternatives (IIA). As the name implies, IIA means that the odds ratio between any two alternatives is independent of other unconsidered alternatives ${ }^{14}$. In the context of our analysis, this meant that the odds ratio between choosing S13 and S15 is independent of W13 or W15. While this property is convenient for estimation purposes, its failure would invalidate our estimation results thus far. It is imperative, then, that we test for evidence of this property. If the test indicates that IIA fails, then we would need to resort to alternative estimation methods, a relatively simple one of which is known as the nested logit (NL) model. It turned out that a simple way to conduct the test was to place a particular restriction on the yet-to-beemployed NL model. 
To set up the NL model, we assumed that consumers make choices in two steps: firstly, they choose the engine size $(1.3 \mathrm{cc}$ or $1.5 \mathrm{cc})$, and then they choose the car model (Saga or Wira). This assumption was made due to our belief that when planning to buy cars that are more or less the same (Saga and Wira are in the same segment of the automobile market), consumers will have a limited price range in mind and this price range can be approximated by the engine size. If we let $i=1,2$ to be the index for the engine size (i.e. 1 for $1.3 \mathrm{cc}$ and 2 for $1.5 \mathrm{cc}$ ) and $j=1,2$ for the car model (i.e. 1 for Saga and 2 for Wira), then a NL model can be written as

$$
\operatorname{Prob}\left(y_{i}=j \mid x_{\mathrm{ij}}^{\prime} \beta\right)=\left[\frac{\exp \left(\mathrm{x}_{\mathrm{i}}^{\prime} \beta\right)}{\sum_{\mathrm{j}=1}^{2} \exp \left(\mathrm{x}_{\mathrm{ij}}^{\prime} \beta\right)}\right] \cdot\left[\frac{\exp \left(\tau_{\mathrm{i}} \mathrm{IV}_{\mathrm{i}}\right)}{\sum_{\mathrm{i}=1}^{2} \exp \left(\tau_{\mathrm{i}} \mathrm{IV} \mathrm{V}_{\mathrm{i}}\right)}\right] .
$$

where the first bracketed term is the probability of choosing the $j^{\text {th }}$ model conditional on choosing the $\mathrm{i}^{\text {th }} \mathrm{cc}$, the second bracketed term is the probability of choosing the $\mathrm{i}^{\text {th }} \mathrm{cc}, \tau$ is a vector of parameters, and $I V$ is called the inclusive value, defined as the log of the denominator of the first bracketed term. It can be shown that, if $\tau=1$, the above NL model reduces to the CL model in Equation 5. Hence, the null hypothesis of IIA can be written as $\mathrm{H}_{0}: \tau=1$. If this null hypothesis can be rejected, then we would conclude that IIA fails, and thus proceed with the framework in Equation 7. Given the same data, we conducted a NL analysis using the maximum likelihood method.

As reported in Table 4, the results showed that a) the intercept coefficients -(i.e., the estimated coefficients of two car models $)^{15}$ enter with the Onegative signs and significant at the $1 \%$ level, and b) the (common) slope coefficient (i.e., the estimated coefficient of the price variable) enters with the negative sign and significant at the 1\% level. Furthermore, the estimated coefficient of the inclusive value was significantly less than 1 , which suggested that $\tau$ cannot be restricted to 1 . The calculated chi-squared value for $\tau=1$ was equal to 12.97. Again, since this value exceeded the corresponding critical chi-squared value of 3.84, the null of IIA can be rejected. As before, this implied that the NL model is preferred to the CL model.

Table 4

Nested Logit Estimation Based on Engine Size

\begin{tabular}{cccc}
\hline Variables & Coefficient & Std Error & $\mathrm{z}$ \\
\hline S13 & $-5.8892^{*}$ & 1.3996 & -4.21 \\
S15 & $-15.7673^{*}$ & 2.9524 & -5.34 \\
Price & $-2.1723^{*}$ & 0.4535 & -4.79 \\
IV & $0.8808^{*}$ & 0.0242 & 36.37 \\
\hline
\end{tabular}

Note. The asterisk * indicates that the coefficient is significant at the $1 \%$ level. 
Given the parameter estimates of the NL model in Table 4, we proceeded with the cross-price discrete change analysis. As reported in Table 6, the general result was far from clear-cut. In some cases, we found evidence that two given car models were substitutes to each other (the estimates were positive and statistically significant). In other cases, however, we found no evidence that two given cars were substitutes to each other (i.e. the estimates were positive but insignificant). In some other cases, unfortunately, we do not obtain any results at all ${ }^{16}$.

Again, the specific results can be decomposed into the impact of a discrete change in the price of any one model on the probability of buying other car models. Firstly, a RM1000 increase in the price of S13 is expected to increase the probability of buying W13 by $47 \%$, but no results were obtained on the impact of the price rise in S13 on each S15 and W15. Secondly, a RM1000 increase in the price of S15 is expected to increase the probability of buying S13 and W13 by less than $0.01 \%$, but there was no evidence that the price rise in S15 affects the probability of buying W15. Thirdly, a RM1000 increase in the price of W13 is expected to increase the probability of buying S13 by $14.5 \%$. For each $S 15$ and $\mathrm{W} 15$, however, the impact of the price rise in W13 is less than $0.01 \%$. Finally, a RM1000 increase in the price of W15 is expected to increase the probability of buying W13 by less than $0.01 \%$. However, there was no evidence that the price rise in W15 affects the probability of buying S13 and S15.

Table 5

Cross-Price and Own-Price Discrete Change Based on Engine Size

\begin{tabular}{ccccc}
\hline \multirow{2}{*}{$\begin{array}{c}\text { Independent } \\
\text { Variable }\end{array}$} & \multicolumn{4}{c}{ Dependent Variable } \\
\cline { 2 - 5 } & S13 & S15 & W13 & W15 \\
\hline \multirow{2}{*}{ PS13 } & $-0.4708^{*}$ & - & $0.4709^{*}$ & - \\
& $(-5.24)$ & $-0.1449^{*}$ & $0.0000^{*}$ & 0.0000 \\
& $0.0000^{*}$ & $(-7.86)$ & $(36.38)$ & $(0.04)$ \\
\hline \multirow{2}{*}{ PS15 } & $(36.40)$ & $0.0000^{*}$ & $-0.0000^{*}$ & $0.0000^{*}$ \\
& $0.1448^{*}$ & $(36.42)$ & $(-36.37)$ & $(36.39)$ \\
\hline \multirow{2}{*}{ PW13 } & $(7.85)$ & 0.0000 & $0.0000^{*}$ & $-0.0000^{*}$ \\
& 0.0000 & $(0.06)$ & $(36.38)$ & $-36.36)$ \\
\hline \multirow{2}{*}{ PW15 } & $(0.29)$ & & & \\
\end{tabular}

Note. Figures in parentheses are the z-values. The asterisk * indicates that the coefficient is significant at the $1 \%$ level. PS13, PS15, PW13, and PW15 refer to the price of respective models.

For the own-price discrete change analysis, we found that a) a RM1000 rise in the price of $\mathrm{S} 13$ reduces the probability of buying it by $47 \%, \mathrm{~b}$ ) a RM1000 rise in the price of S15 reduces the probability of buying it by 
$14.5 \%, \mathrm{c})$ a RM1000 rise in the price of either W13 or W15 has a very small (albeit significant) impact on the probability of buying the respective car. Again, these results were consistent with the basic demand theory.

\section{DISCUSSION}

When we started our analysis, we applied the CL model and the results obtained are displayed in Table 3. We concluded from the cross-price discrete change results that the four car models are substitutes for each other ${ }^{17}$.

However, the CL model is characterised by the property of the -independence of irrelevant alternatives (IIA). If this property holds, then the estimation results based on the CL model are valid. If this property fails to hold, however, then the CL-based results break down. To determine whether the IIA property holds, we employed a specification test. Since the test showed that IIA was untenable, an alternative estimation "method called the NL model was employed. The results obtained are shown in Table 5. We concluded from the cross-price discrete change results that two car models are substitutes to each other in seven out of twelve cases. For the remaining five cases, we found either no evidence of substitutability or no evidence at all.

If we compare the baseline results (Table 3) to the robustness results (Table 5), and if we use the 5\% cut-off point to distinguish between close and distant (or poor) substitutes, we found that the baseline results were robust to the IIA violation in five out of twelve cases only (i.e. S15 vs. S13, S15 vs. W13, W13 vs. S15, W13 vs. W15, and W15 vs. W13) ${ }^{18}$. In the "remaining seven cases, the baseline results were either nonrobust (i.e., S13 vs. W13, S15 vs. W15, W13 vs. S13, W15 vs. S13, and W15 vs. S15) or no evaluation could be made (i.e. S13 vs. S15 and S13 vs. W15). In light of these mixed results, we concluded that our baseline results are not robust to the IIA violation. Accordingly, our interpretation must be made from the perspective of NL estimation results.

If we consider the NL results in a bilateral fashion, we can make several economic interpretations and derive several policy implications. Firstly, the bilateral results on S13 and S15 (i.e., S13 vs. S15 and S15 vs. S13) preclude us from making any economic interpretations as well as stating any policy implications. Secondly, the bilateral results on S13 and W13 showed that both models are substitutes for each other. This means that 
Proton may face the risk of losing the sales of W13 if it decides to cut the price of S13, and vice versa. Take note, however, that the impact is asymmetric in the sense that a price cut in S13 has a larger effect on the sales of W13 than a price cut in W13 does on the sales of S13.

Thirdly, the bilateral results on S13 and W15 indicated that there is no evidence that both models are substitutes for each other. This means that Proton may reduce the price of S13 without having to worry about the adverse impact of such a policy action on the sales of W15, and vice versa. Fourthly, the bilateral results on S15 and W13 revealed that both models were poor substitutes for each other. This means that Proton may decrease the price of S15 without worrying too much about the adverse impact of such a move on the sales of W13, and vice versa.

Fifthly, the bilateral results on S15 and W15 indicated that there is no evidence that both models were substitutes for each other. This means that Proton may cut the price of S15 without having to worry much about its adverse impact on the sales of W15, and vice versa. Finally, the bilateral results on W13 and W15 showed that both models were poor substitutes for each other. This means that Proton may decrease the price of W13 without worrying too much about its adverse impact on the sales of W15, and vice versa.

Given the bilateral results, we may proceed by generalising the impact of a price-cut policy in a multilateral fashion. Firstly, if Proton decides to cut the price of S13, then it would probably risk losing the sales of W13 only. Secondly, if Proton chooses to decrease the price of S15, then it would probably not risk losing the sales of other models. Thirdly, if Proton reduces the price of W13, then it would probably risk losing the sales of S13 only. Finally, if Proton slashes the price of W15, then it would probably not risk losing the sales of other models ${ }^{19}$.

\section{CONCLUSION}

Our empirical analysis on the consumer choice of some selected automobiles in Malaysia produced the following cross-price results. Firstly, the sales of Saga 1.3cc seem to be affected by a change in the price of Wira 1.3cc only. Secondly, the sales of Saga 1.5cc do not seem to be affected by a change in the price other models. Thirdly, the sales of Wira $1.3 \mathrm{cc}$ appear to be affected by a change in the price of Saga 1.3cc only. Finally, the sales of Wira 1.5cc do not appear to be affected by a change in 
the price of other models. Our empirical results lead us to the following conclusion: except for Saga 1.3cc and Wira 1.3cc, there is little or no evidence that all of the car models under consideration are substitutes to each other in a pairwise comparison. Accordingly, as far as the pricing policy is concerned, Proton needs to worry about the adverse impact of a price cut in Saga 1.3cc on the sales of Wira 1.3cc only, and vice versa.

Our empirical analysis is not without limitations. The first caveat is that our study focused on the price variables only. Given the choices among four car models, one additional variable that is worth examining is design type (i.e. sedan or manual). As discussed in Section 4 and shown (sec Figure 3 in Apendix B) however, the omission of this potentially important variable was due to the lack of price data on the manual and sedan version of Saga 1.5cc. If we can recover the needed data from EON "or other Proton distributors, we would be able to incorporate design type as another explanatory variable, and possibly obtain an entirely different set of results.

D Another limitation is that the period of analysis was restricted to three "years only (2000-2002). Given the fact that the price of national cars is constant within a year, our estimation results might suffer from the lack of price variation. Again, the culprit behind this unsatisfactory choice was data limitations. In most cases (see Figure 3), the price data for any model were available up to a few years only. Again, this shortcoming

can be overcome if we can recover the data from EON or other Proton "distributors, and yet again, we might obtain an entirely new set of results with a greater price variation.

\section{END NOTES}

1. Consider the price of a reasonably low-cost car on the road today, Saga. At the moment, this car is priced at approximately RM40,000. If a person buys the car on a loan basis for a period of 7 years, pays a minimum deposit of $10 \%$ and incurs an interest of $5 \%$ per year, he or she needs to pay approximately RM700 per month. Suppose an average household in Malaysia earns about RM2,000 per month. Then, the car expenditures constitute about $30 \%$ of his or hers monthly income.

2. The Saga model was face-lifted in 1992 and was renamed Iswara. The Satria model was face-lifted in 2006 and was renamed Satria Neo. Of these models, Putra and Tiara were failures. Their production ceased in 2000 and 2001, respectively. 
3. Table 1 in Appendix A shows the quantity sold of all models, the debut of each model, and the best-selling models on the road based on a few alternative measures.

4. For example, suppose a consumer faces a choice between Saga and Wira. Hence, the dependent variable is a dummy variable which takes the value of 1 if he chooses Saga and 0 if he chooses Wira. Since the dependent variable is a dummy, it has to be interpreted in probabilistic sense; i.e. the probability of buying Saga is, say, $80 \%$.

5. The conditional logit model was introduced into the DCM by McFadden (1973), a co-recipient of Nobel Prize in Economic Science in 2000 .

6. Since car prices do not change much during a one-year period in Malaysia, multi-period data are needed in order to allow for price variation, which is essential for our empirical analysis.

7. Common sense would suggest that consumers approach the market with a reasonably limited price range in mind, given their budgets. Hence, they are not contemplating choosing between, say, Kelisa and Wira.

8. Note that each $x j$ is indexed by $i$ to account for the possibility that the price of a given model faced by a consumer may differ from that faced by another consumer.

9. An implicit assumption embodied in Equation (5) is that all price variables share a common slope parameter but different intercept terms. For identification, the intercept term for xi4 is assigned the value of zero.

10. See Appendix $C$ for the exact calculation of Equation (6) for a specific model.

11. This concept is borrowed from basic demand theory, which states that two goods are substitutes to each other if an increase in the price of one good has a positive impact on the quantity demanded of another good.

12. Note that we assumed one consumer buys one car only; there is no repeat purchase. In view of the car price and the short time period, this is a plausible assumption to make. 
13. Recall that the intercept term for the reference category, W15, is set to zero. See end note 9.

14. The odds ratio refers to the ratio of the probability of choosing one alternative (say, Prob $(y i=j \mid$. $)$ ) to the probability of choosing another alternative (say, Prob (yi $=\mathrm{k}$ l.)).

15. Now there are two reference categories, W13 and W15, which implies that their intercept terms are set to zero.

16. The failure to obtain an estimate can be attributed to the fact that we are dealing with a nonlinear model. When a nonlinear model (such as the one we use) is estimated, there is no closed-form solution. To obtain the solution, some iterative algorithm is employed. In some cases, the algorithm leads us to a solution; in other cases, the algorithm fails to obtain the solution.

17. The own-price discrete change of all four models was found to be consistent with the demand theory (i.e. displaying a negative relationship of price and quantity).

18. S15 vs. S13 refers to the impact of a price change in S15 on the probability of buying S13, and so on.

19. If we discuss these in terms of a price-rise policy, all of the above results need to be overturned.

\section{REFERENCES}

Berkovec, J., \& Rust, J. (1985). A nested logit model of automobile holdings for one vehicle households. Transportation Research B, 19(4), 275-285.

Choo, S., \& Mokhtarian, P. L. (2004). What type of vehicle do people drive? The role of attitude and lifestyle in influencing vehicle type choice. Transportation Research A, 38(3), 201-222.

Franses, P. H., \& Paap, R. (2001). Quantitative models in marketing research. New York: Cambridge University Press.

Greene, W. J. (2008). Econometric Analysis (6th ed.). Pearson Prentice Hall.

Lave, C. A., \& Train, K. (1979). A disaggregate model of auto-type choice. Transportation Research A, 13(1), 1-9.

Long, J. S. (1997). Regression models for categorical and limited dependent variables. Sage. 
Malaysian Automotive Association. (2007). Summary of sales and production data. Retrieved November 25, 2007 from http://www. maa.org.my/info_summary.htm/

Malaysian Industrial Development Authority. (2007). Business opportunities: Malaysia's automotive industry. Retrieved November 25, 2007 from http://www.mida.gov.my/

Mannering, F., \& Winston, C. (1985). A dynamic empirical analysis of household vehicle ownership and utilization. Rand Journal of Economics, 16(2), 215-236.

Mannering, F., Winston, C. \& Starkey, W. (2002). An exploratory analysis of automobile leasing by U.S. Households. Journal of Urban Economics, 52(1), 154-176.

Manski, C. F., \& Sherman, L. (1980). An empirical analysis of household choice among motor vehicles. Transportation Research A, 14, 349366.

McFadden, D. (1973). Conditional logit analysis of qualitative choice behaviour. Frontiers in Econometrics, P. Zarembka (ed.) New York: Academic Press.

Ministry of Finance (various issues). Economic Report. Kuala Lumpur: Pencetakan Nasional.

Train, K. (1980). A structured logit model of auto ownership and mode choice. Review of Economic Studies, 47, 357-370. 


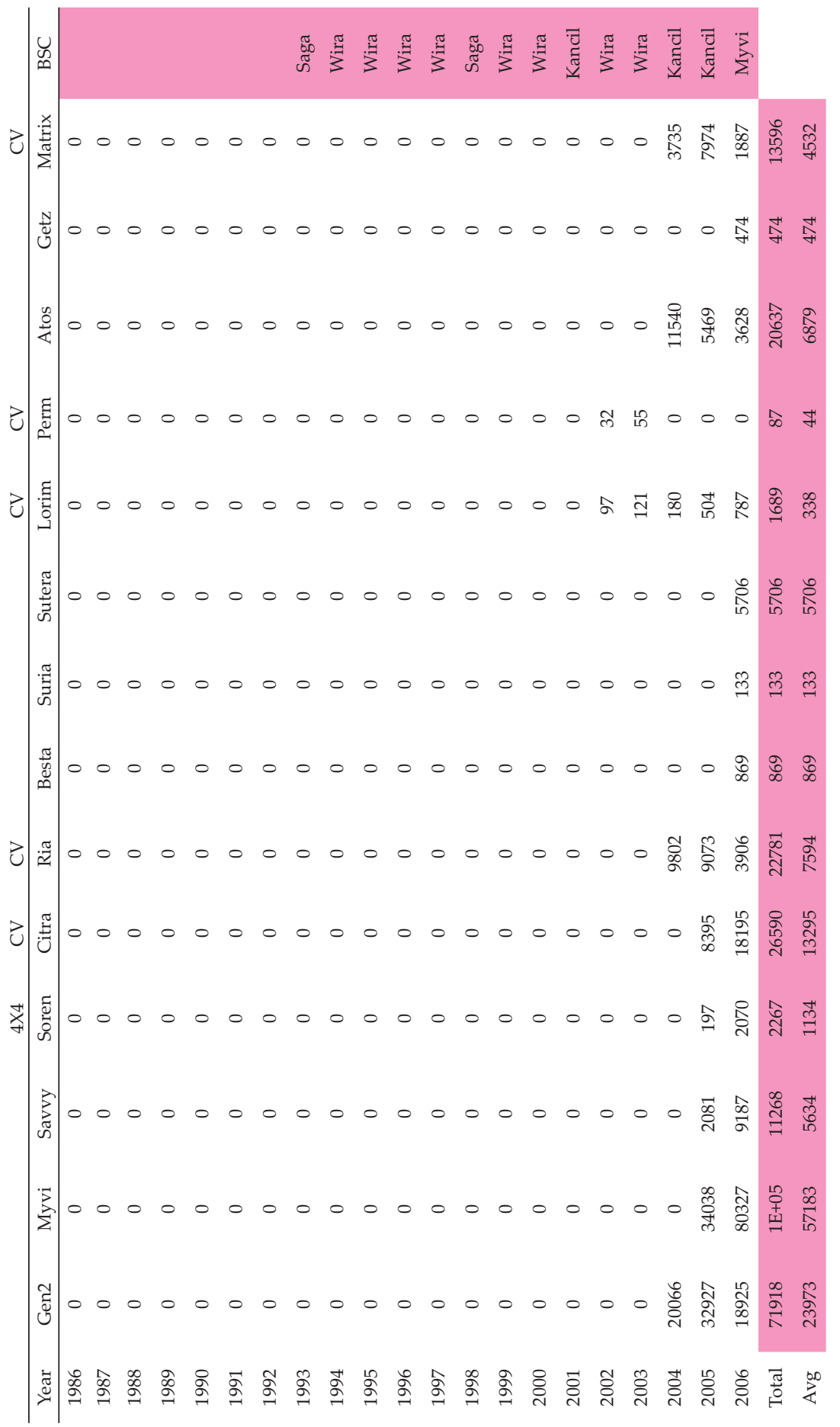




\section{APPENDIX C: Calculation of Cross-Price Discrete Change for Conditional Logit}

Let $P_{i j}$ denote the probability of choosing $j^{\text {th }}$ model by $i^{\text {th }}$ consumer; i.e. $P_{i j} \equiv \operatorname{Prob}\left(y_{i}=j \mid \mathrm{x}_{\mathrm{ij}}^{\prime} \beta\right)$. Then, expanding Equation 5 for $\mathrm{S} 13$ yields:

$$
P_{i 1}=\frac{\exp \left(\beta_{01}+\beta_{1} x_{i 1}\right)}{\exp \left(\beta_{01}+\beta_{1} x_{i 1}\right)+\exp \left(\beta_{02}+\beta_{1} x_{i 2}\right)+\exp \left(\beta_{03}+\beta_{1} x_{i 3}\right)+\exp \left(\beta_{04}+\beta_{1} x_{i 4}\right)},
$$

where the denominator consists of the sum of the exponential function of all four car models and the numerator contains the exponential function of car model $j$. Note that the intercept terms vary across car models but the slope parameters are constant. For identification, the intercept term for W15 is set equal to zero (i.e., $\beta_{04}=0$ ).

Given the above equation, the impact of a change in the price of S15 $(j=2)$ on the probability of buying S13 is given by

$$
\begin{aligned}
& \frac{\Delta P_{i 1}}{\Delta \mathrm{x}_{\mathrm{i} 2}}=P_{i||_{x_{1}+\Delta x_{2}}}-\mathrm{P}_{\mathrm{i} \mid \mathrm{x}_{12}} \\
& =\left[\frac{\exp \left(\beta_{01}+\beta_{1} \bar{x}_{i 1}\right)}{\exp \left(\beta_{01}+\beta_{1} \bar{x}_{i 1}\right)+\exp \left(\beta_{02}+\beta_{1}\left[\bar{x}_{i 2}+\Delta x_{i 2}\right]\right)+\exp \left(\beta_{03}+\beta_{1} \bar{x}_{i 3}\right)+\exp \left(\beta_{1} \bar{x}_{i 4}\right)}\right] \\
& -\left[\frac{\exp \left(\beta_{01}+\beta_{1} \bar{x}_{i i}\right)}{\exp \left(\beta_{01}+\beta_{1} \bar{x}_{i 1}\right)+\exp \left(\beta_{02}+\beta_{1} \bar{x}_{i 2}\right)+\exp \left(\beta_{03}+\beta_{1} \bar{x}_{i 3}\right)+\exp \left(\beta_{1} \bar{x}_{i 4}\right)}\right],
\end{aligned}
$$

where the bar over each price variable indicates that the price variables are evaluated at some specific values. In our analysis, we picked the initial value (i.e., the 2000 value) for all car models. Note also that $\Delta \mathrm{x}_{\mathrm{i} 2}$ is the amount by which the initial value of the price of S15 has changed. We picked $\Delta \mathrm{x}_{\mathrm{i} 2}=1$. With the price variable expressed in thousands of ringgit, $\Delta \mathrm{x}_{\mathrm{i} 2}=1$ is equivalent to RM1000. 


\section{APPENDIX D: Calculation of Cross-Price Discrete Change for Nested Logit}

Let $P_{i j}$ denote the probability of choosing $i^{\text {th }}$ model and $j^{\text {th }}$ cc. Then, expanding Equation 7 for S13 yields:

$$
P_{11}=\left[\frac{\exp \left(\beta_{01}+\beta_{1} x_{11}\right)}{\exp \left(\beta_{01}+\beta_{1} x_{11}\right)+\exp \left(\beta_{02}+\beta_{1} x_{12}\right)}\right] \cdot\left[\frac{\tau_{1}\left[\exp \left(\beta_{01}+\beta_{1} x_{11}\right)+\exp \left(\beta_{02}+\beta_{1} x_{12}\right)\right]}{\tau_{1}\left[\exp \left(\beta_{01}+\beta_{1} x_{11}\right)+\exp \left(\beta_{02}+\beta_{1} x_{12}\right)\right]+\tau_{2}\left[\exp \left(\beta_{03}+\beta_{1} x_{21}\right)+\exp \left(\beta_{04}+\beta_{1} x_{22}\right)\right]}\right],
$$

where the first bracketed term consists of the probability of choosing $1.3 \mathrm{cc}$ within Saga model, the second bracketed term consists of the probability of choosing Saga model, $\tau_{1}$ is a parameter corresponding to the Saga "choice, and $\tau_{2}$ is a parameter corresponding to the Wira choice. Note that the above nested logit model reduces to the conditional logit model if $\tau_{1}=\tau_{2}=1$. As in the conditional logit model, the intercept terms vary across car models but the slope parameters are constant. For identification, the Dintercept terms for S15 and W15 were set equal to zero (i.e., $\beta_{02}=\beta_{04}=0$ ).

Given the above equation, the impact of a change in the price of $S 15$ ( $j=$ 2 ) on the probability of buying S13 is given by

$$
\begin{aligned}
& \frac{\Delta P_{11}}{\Delta x_{12}}=P_{\|\|_{x_{1}}}-P_{\|\|_{x_{2}}+\Delta \Delta_{r_{2}}}
\end{aligned}
$$

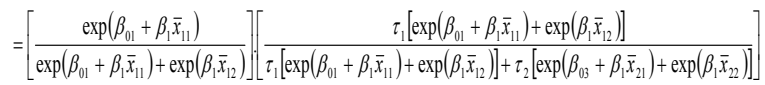

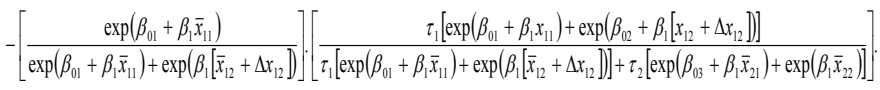

The bar over each price variable indicates that the price variables are evaluated at some specific values. 